\title{
Small cross-sectional survey of composite restoration attributes associated with choices for replacement
}

\author{
Alessandra Ramos Parpaiola ${ }^{(a)}$ \\ Priscilla Santos Guimarães ${ }^{(b)}$ \\ Fabiana Mantovani Gomes \\ França $\mathbf{a}^{(\mathrm{c})}$ \\ Roberta Tarkany Basting ${ }^{(\mathrm{d})}$ \\ (a) MSc Student; (c) PhD, Professor; (d) ScD, \\ PhD, Professor - Department of Restorative \\ Dentistry, São Leopoldo Mandic Research \\ Center, Campinas, SP, Brazil. \\ (b) $\mathrm{ScD}$, Professor, Department of Restorative \\ Dentistry and Dental Materials, School \\ of Health and the Environment (FAESA), \\ Vitória, ES, Brazil.
}

\begin{abstract}
The aim of this work was to present a small cross-sectional survey of composite restoration clinical attributes associated with choices for replacement. Ninety-four composite fillings selected to be replaced were included in this study. A questionnaire was filled out after each procedure in order to assess the clinical conditions that indicated the restoration replacement (marginal staining, unsatisfactory restoration anatomy, marginal fracture, fractured restoration body, painful symptoms, dental fracture, composite discoloration and/or restoration displacement). These conditions could be combined. The chi-square and Exact Fisher tests were performed to analyze the different variables $(\mathrm{p}<0.05)$. The results showed that composite shade discoloration was the main cause of restoration replacement $(63.8 \%)$. Marginal staining (50\%), unsatisfactory restoration anatomy $(50 \%)$, marginal fracture $(14.9 \%)$, painful symptoms $(8.5 \%)$, fractured restoration body $(4.3 \%)$, dental fracture $(1.1 \%)$ and total displacement of the restoration $(1.1 \%)$ were conditions that could be associated. The main cause of dental composite restoration replacement was material shade mismatch with the dental structure (anterior teeth) or marginal staining and unsatisfactory restoration shape (posterior teeth). Marginal staining and composite shade discoloration contrasting with dental structure were related to the presence of caries.
\end{abstract}

Descriptors: Clinical trial; Esthetics; Dental leakage.

\footnotetext{
Corresponding author:

Roberta Tarkany Basting

Faculdade de Odontologia e Centro de Pesquisas Odontológicas São Leopoldo Mandic

Departamento de Odontologia Restauradora

- Dentística

Rua José Rocha Junqueira, 13,

Bairro Ponte Preta

Campinas - SP - Brazil

CEP: 13045-755

E-mail: rbasting@yahoo.com
}

Received for publication on Dec 08, 2007

Accepted for publication on Dec 18, 2008 


\section{Introduction}

In the early 1960s, Bowen started his research using epoxy resins, which presented limited clinical use, culminating in the development of dental composite. Since then, significant improvements in the manipulation, adhesion, mechanical resistance, wear resistance and shade stability characteristics have been observed. ${ }^{1}$ However, differences still persist between the properties of the materials and those of dental tissues. The hybridization between the restorative material and the dental substrate is the base for interface maintenance. However, it is known that leakage is an inevitable process, and polymerization shrinkage, thermal expansion coefficient and elastic modulus are the main physical properties of dental composites that influence adhesion durability. ${ }^{2,3}$

The differences between the physical properties of teeth and those of restorative materials lead to the formation of gaps at the tooth/restoration interface and consequent marginal microleakage, which is considered the main cause of failures in dental composite restorations. ${ }^{4}$ The main clinical signs that indicate microleakage are marginal staining of the restoration, recurrent caries, injuries to the dentinpulp complex and marginal fractures. , $^{3,-10}$

In view of the large number of clinical signs suggestive of marginal microleakage, it is necessary to establish which of these signs really indicate the replacement or repair of the restoration. Thus, the aim of this work was to present a small cross-sectional survey of the clinical attributes of composite restorations that are associated with the decision for replacement.

\section{Material and Methods}

Patients who presented the need to replace one or more direct dental composite restorations in anterior or posterior teeth were assessed, after the project was approved by the local Research Ethics Committee (Process No. 05/189). Patients of both genders, ages ranging from 19 to 62 years old, treated during the period from March to December 2005, at the Dentistry Course of the FAESA (School of Health and the Environment) Dental Clinic were selected for this study.
The patients were assessed by clinical examination after prophylaxis, drying and illuminating the region with a reflector. The restorations were evaluated by 3 calibrated examiners who are faculty at the University. The clinical conditions were recorded on a specific chart in accordance with the following criteria:

- Presence of marginal staining (Figure 1);

- presence of unsatisfactory restoration anatomy (Figure 2);

- presence of marginal fracture of the restoration (Figure 3);

- presence of restoration body fracture (Figure 4);

- presence of painful symptoms;

- presence of tooth fracture;

- presence of unsatisfactory composite shade (Figure 5);

- presence of a displacement of the restoration.

The decision to indicate replacement was based exclusively on the clinical criteria. When one of these conditions was found, and there was no possibility of repairing it, replacement was indicated; there could also be a combination of clinical signs. So, more than one reason for replacement per restoration could be recorded (not only the main reason for replacement). Radiographs were also taken to determine the presence of caries around restorations.

The presence of caries below the replaced restoration was also recorded. The criteria used for caries diagnosis was the presence of soft dentin tissue when an excavator was used. The approximate date when the restoration was made was recorded after

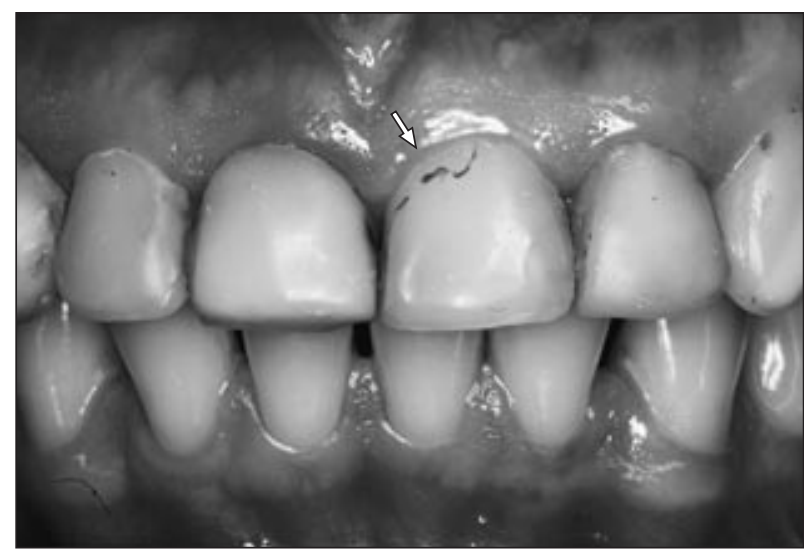

Figure 1 - Marginal staining. 


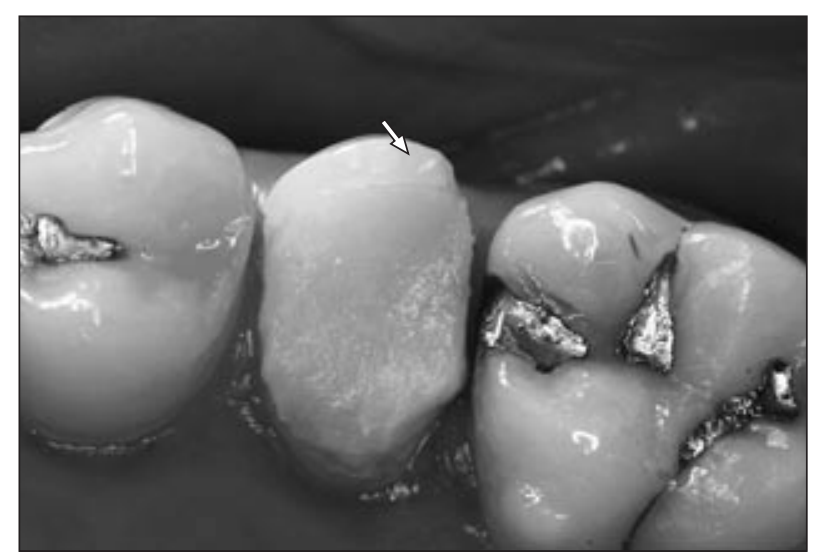

Figure 2 - Unsatisfactory restoration shape.

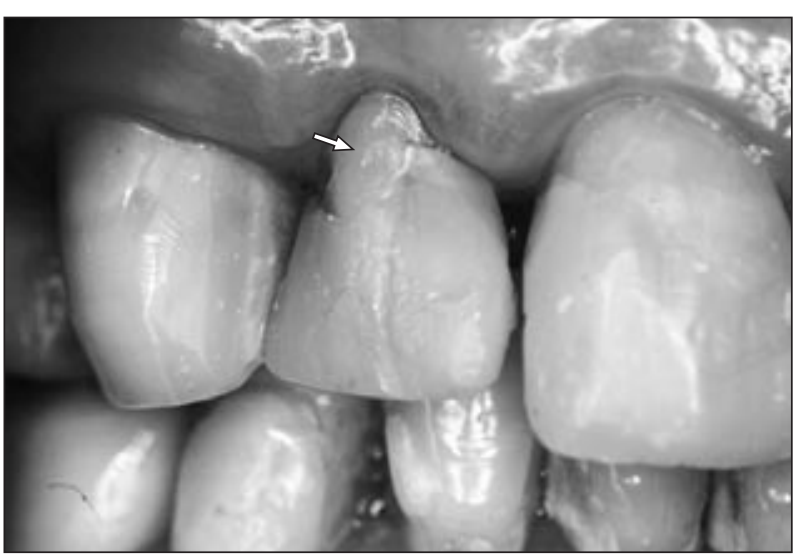

Figure 4 - Restoration body fracture.

information was provided by the patients.

The non-parametric chi-squared $\left(\chi^{2}\right)$ and the Fisher exact tests were used to analyze a possible association among the variables with a 5\% significance level.

\section{Results}

Ninety-four (94) restorations to be replaced in anterior and posterior teeth were evaluated. The distribution of the restorations in accordance with Black classification and location is shown in Table 1. The restorations comprised approximately the same amount in anterior and posterior segments: $51 \%(\mathrm{n}=48)$ and $49 \%(\mathrm{n}=46)$, respectively.

Of the clinical conditions assessed, it was found that composite discoloration was observed in $63.8 \%$

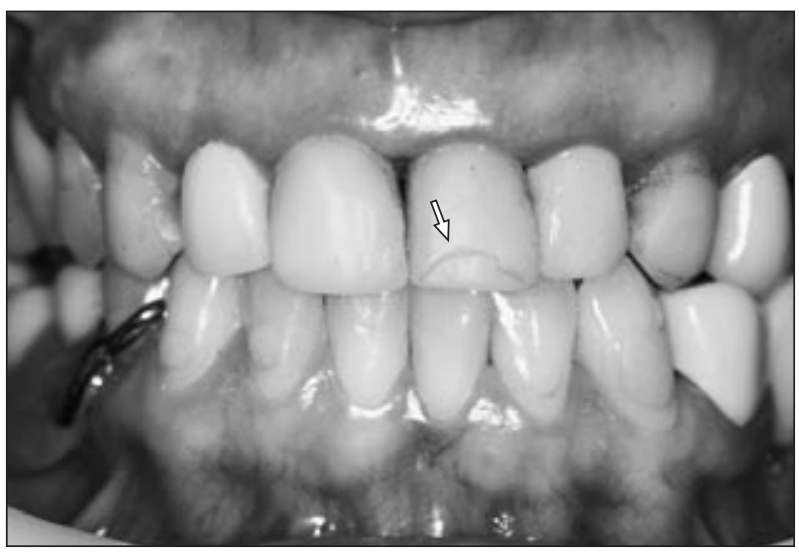

Figure 3 - Marginal fracture.

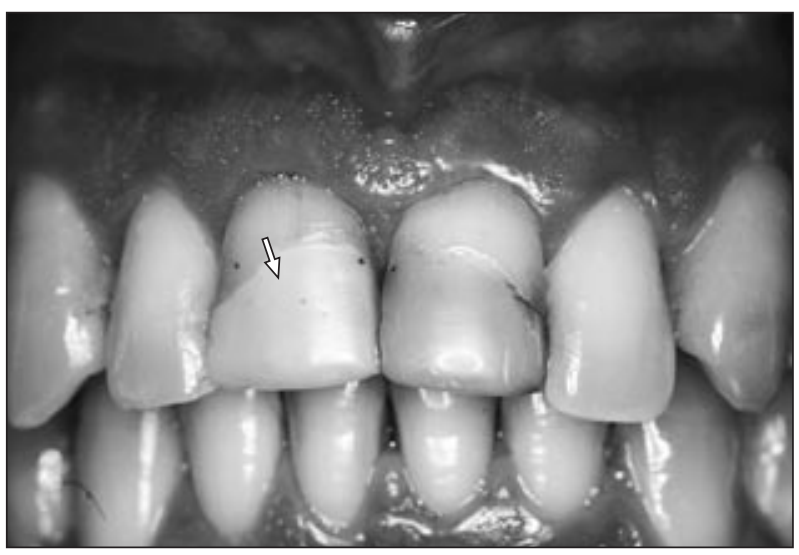

Figure 5 - Unsatisfactory material shade.

Table 1 - Distribution of frequencies according to Black cavity classification and surfaces affected.

\begin{tabular}{l|c|c}
\hline \multicolumn{1}{c|}{ Cavity Classification } & Frequency & $\%$ \\
\hline Class I & 24 & 25.5 \\
\hline Class II (DO/MO) & 12 & 12.8 \\
\hline Class II (MOD) & 4 & 4.3 \\
\hline Class III & 31 & 32.9 \\
\hline Class IV & 13 & 13.9 \\
\hline Class V & 10 & 10.6 \\
\hline Total & 94 & 100.0 \\
\hline \multicolumn{1}{c|}{ Surfaces affected } & & \\
\hline Proximal & 47 & 50.0 \\
\hline Occlusal & 36 & 38.3 \\
\hline Vestibular & 27 & 28.7 \\
\hline Lingual & 22 & 23.4 \\
\hline
\end{tabular}


$(\mathrm{n}=60)$. When relating the clinical signs present in anterior restorations, material shade mismatch was the one most frequently observed in $77 \%(n=37)$ of the cases, followed by marginal staining and unsatisfactory restoration shape, both present in $45.8 \%$ $(\mathrm{n}=22)$. The clinical signs observed in posterior restorations indicated for replacement were material shade mismatch in $50 \%$ of the cases $(\mathrm{n}=23)$ and marginal staining and unsatisfactory restoration shape, both in $54.3 \%(\mathrm{n}=25)$ of the cases (Table 2$)$.

In $61.7 \%$ of the cases, the presence of caries was observed after the restorative material was removed

Table 2 - Distribution of frequencies according to the clinical condition found (total and for anterior and posterior teeth)*.

\begin{tabular}{|c|c|c|}
\hline Clinical condition (total) & Frequency & $\%$ \\
\hline Material shade mismatch & 60 & 63.8 \\
\hline Marginal staining & 47 & 50.0 \\
\hline Unsatisfactory restoration shape & 47 & 50.0 \\
\hline Fractured restoration margins & 14 & 14.9 \\
\hline Painful symptoms & 8 & 8.5 \\
\hline Fractured restoration body & 4 & 4.3 \\
\hline Tooth fracture & 1 & 1.1 \\
\hline Displacement of the restoration & 1 & 1.1 \\
\hline \multicolumn{3}{|l|}{ Clinical condition (anterior teeth) } \\
\hline Material shade mismatch & 37 & 77.0 \\
\hline Marginal staining & 22 & 45.8 \\
\hline Unsatisfactory restoration shape & 22 & 45.8 \\
\hline Fractured restoration margins & 3 & 6.3 \\
\hline Painful symptoms & 0 & 0 \\
\hline Fractured restoration body & 0 & 0 \\
\hline Tooth fracture & 0 & 0 \\
\hline Displacement of the restoration & 1 & 2.1 \\
\hline \multicolumn{3}{|l|}{ Clinical condition (posterior teeth) } \\
\hline Material shade mismatch & 23 & 50 \\
\hline Marginal staining & 25 & 54.3 \\
\hline Unsatisfactory restoration shape & 25 & 54.3 \\
\hline Fractured restoration margins & 11 & 23.9 \\
\hline Painful symptoms & 9 & 19.5 \\
\hline Fractured restoration body & 4 & 8.7 \\
\hline Tooth fracture & 1 & 2.2 \\
\hline Displacement of the restoration & 0 & 0 \\
\hline
\end{tabular}

*The restorations observed could present one or more clinical signs.
(Table 3). Caries lesions were diagnosed in $79 \%$ $(\mathrm{n}=37)$ of the restorations with marginal staining, $70 \%(\mathrm{n}=42)$ of the restorations with shade mismatch and $66 \%(n=31)$ of restorations with unsatisfactory shape (Table 4).

In regard to the approximate date on which the restoration indicated for replacement was inserted, only $46.8 \%(n=44)$ of the patients provided this information and assumed that $70.4 \%$ of the restorations had been made less than 5 years previously (Table 5). The other patients did not know exactly when the restoration had been made.

The chi-squared test $\left(\chi^{2}\right)$ showed the association of the variables "Marginal Staining" and "Material shade mismatch" with "Carious Tissue" during removal for replacement of the composite restoration (Table 6).

Table 3 - Distribution of frequencies according to the presence of caries after removal of the restoration.

\begin{tabular}{c|c|c}
\hline Caries & Frequency & $\%$ \\
\hline Yes & 58 & 61.7 \\
\hline No & 36 & 38.3 \\
\hline Total & 94 & 100.0 \\
\hline
\end{tabular}

Table 4 - Distribution of frequencies according to the presence of caries and marginal staining, shade mismatch and unsatisfactory shape.

\begin{tabular}{c|c|c|c}
\hline \multirow{2}{*}{$\begin{array}{c}\text { Caries lesion } \\
\text { associated with }\end{array}$} & \multicolumn{2}{|c|}{ Frequency (\%) } & \multirow{2}{*}{ Total (\%) } \\
\cline { 2 - 3 } & Yes & No & \\
\hline Marginal staining & $37(79)$ & $10(21)$ & $47(100.0)$ \\
\hline Shade mismatch & $42(70)$ & $18(30)$ & $60(100.0)$ \\
\hline Unsatisfactory shape & $31(66)$ & $16(34)$ & $47(100.0)$ \\
\hline
\end{tabular}

Table 5 - Distribution of frequencies according to the approximate time at which the replaced restoration was originally inserted.

\begin{tabular}{l|c|c}
\hline \multicolumn{1}{c|}{ Time } & No. of cases & Frequency (\%) \\
\hline Less than 1 year previously & 9 & 20.5 \\
\hline From 1 to 5 years previously & 22 & 50 \\
\hline Over 5 years previously & 13 & 29.5 \\
\hline $\begin{array}{l}\text { Patients reporting approximate } \\
\text { initial restoration date }\end{array}$ & 44 & 100 \\
\hline
\end{tabular}


Table 6 - Study of the relation between the clinical condition and observation of caries.

\begin{tabular}{l|c|l}
\hline \multicolumn{1}{c|}{$\begin{array}{c}\text { Clinical condition } \times \\
\text { Observation of caries }\end{array}$} & Test Statistics- $\chi^{2}$ & p-Valve \\
\hline Marginal staining & 11.525 & $0.001^{*}$ \\
\hline Fractured restoration margins & 0.145 & 0.704 \\
\hline Fractured restoration body & 0.242 & 0.636 (a) \\
\hline Painful symptoms & 2.167 & 0.253 (a) \\
\hline Tooth fracture & 0.627 & 1.000 (a) \\
\hline Material shade mismatch & 4.833 & $0.028^{*}$ \\
\hline Unsatisfactory restoration shape & 0.720 & 0.396 \\
\hline
\end{tabular}

(a) Exact Fisher Test; ${ }^{*}$-Value $<0.05$

\section{Discussion}

In this study, when the clinical signs that were most frequently present in the replaced restoration were analyzed, caries lesions were observed in $79 \%$ of the restorations with marginal staining and $70 \%$ of the cases with material shade mismatch. Marginal staining is mentioned as a clinical sign of microleakage ${ }^{6,8}$ and according to the present results, its clinical presence is a good parameter for indicating esthetic restoration replacement. Other clinical signs have been mentioned, such as tooth discoloration $^{11}$ and marginal fractures. ${ }^{6,12}$ Post-operative sensitivity, recurrent caries, injuries and pulp necrosis are also considered clinical signs of microleakage. ${ }^{6,8,10,13-16}$

When the clinical condition of restorations replaced in anterior and posterior teeth were related, $77 \%(\mathrm{n}=37)$ of the restorations in anterior teeth were replaced because of material shade mismatch, either associated with other factors, or not. In posterior teeth, the main reasons were marginal staining and unsatisfactory restoration anatomy. Li et al. ${ }^{11}$ (2001) affirmed that extensive microleakage could occur around the restoration without it becoming dislocated. In an in vivo study in which composite restorations were followed up for a period of 36 months, ${ }^{6}$ a high retention rate was observed (86\%), even when superficial marginal discoloration and marginal degradation were noted.

In this study, a higher rate of clinical signs that indicated restoration replacement was diagnosed on the proximal surfaces (50\% of cases). In the proxi- mal regions, mainly in Class II cavities in which the gingival margin of the restoration is in dentin or cement, bonding and polymerization procedures are critical. ${ }^{12}$ When the cervical margins of the preparation are located in enamel, the microleakage rate is significantly lower. ${ }^{17-19}$

The presence of marginal leakage is a limiting factor in the longevity of composite restorations. ${ }^{8,20}$ Microleakage can lead to secondary caries, as related by Mjör, Toffenetti ${ }^{21}$ (2000) and Mjör ${ }^{22}$ (2005). The technique for inserting and polymerizing the resin composite is sensitive and time consuming. ${ }^{3}$ The operator's understanding of the bonding mechanism of the resin composite to tooth hard tissues is of fundamental importance for optimizing the performance of the material.

It was observed that $70.4 \%$ of the esthetic restorations that were indicated for replacement had been placed a maximum of 5 years previously. The longevity of composite restorations is a common concern, ${ }^{23}$ but no identification of problems during the restoration procedure (such as the use of an incorrect technique) was performed. In this study, the information about the date of the initial restoration was obtained by a report made by the patients, however, sometimes they were vague and inexact in remembering the time when it was done.

A large number of composite restorations are replaced because of dissatisfaction with esthetics. Material shade alteration was the topic most indicated by the questionnaires in 60 cases, 37 of them being in anterior teeth and 23 in posterior teeth. Material shade mismatch can be due to several factors, such as those occuring during shade selection, and those after restoration placement, such as unsatisfactory hygiene, use of beverages such as coffee and tea, among others that could lead to staining both the restoration and the tooth. In cases in which this staining is slight, polishing the restoration may return its satisfactory esthetic appearance, thus allowing the restoration to be kept for a longer period. Nevertheless, in some situations, this shade alteration is serious and difficult to remove with polishing and may be associated with other clinical signs.

The main cause of composite restoration replacement is the formation of caries, as a result of mar- 
ginal leakage. ${ }^{24}$ It is important that signs and consequences of microleakage be differentiated, so that diagnosis can be made as soon as possible, and that microleakage of a small extent be prevented from developing into severe conditions, such as caries lesions, complete loss of the restoration or even pulp necrosis.

\section{Conclusions}

The main cause of dental composite restoration replacement in anterior teeth was material shade mismatch with the dental structure, while in posterior teeth it was marginal staining and unsatisfactory restoration shape. Marginal staining and material shade mismatch with the dental structure were related to the presence of caries.

leakage microhardness of resin composite restorations. Oper Dent. 2003;28(2):200-6.

14. Chimello DT, Chinelatti MA, Ramos RP, Palma Dibb RG. In vitro evaluation of microleakage of a flowable composite in class V restorations. Braz Dent J. 2002;13(3):184-7.

15. Demarco FF, Ramos OLV, Mota CS, Formolo E, Justino LM. Influence of different restorative techniques on microleakage in class II cavities with gingival wall in cementum. Oper Dent. 2001;26(3):253-9.

16. Glayds S, Meerbeek BV, Lambrechts P, Vanherle G. Microleakage of adhesive restorative materials. Am J Dent. 2001;14(3):170-6.

17. Brunton PA, Kassir A, Dashti M, Setcos JC. Effect of different application and polymerization techniques on the microleakage of proximal resin composite restorations in vitro. Oper Dent. 2004;29(1):54-9.

18. Kubo S, Yokota H, Sata Y, Hayashi Y. Microleakage of selfetching primers after thermal and flexural load cycling. Am J Dent. 2001;14(3):163-9.

19. Loguercio AD, Bauer JRO, Reis A, Grande RH. In vitro microleakage of packable composites in class II restorations. Quintessence Int. 2004;35(1):29-34.

20. Alonso RCB, Sinhoreti MAC, Sobrinho LC, Consani S, de Góes MF. Effect of resin liners on the microleakage of class $\mathrm{V}$ dental composite restorations. J Appl Oral Sci. 2004;12(1):5661.

21. Mjör IA, Toffenetti F. Secondary caries: a literature review with case reports. Quintessence Int. 2000;31(3):165-79.

22. Mjör IA. Clinical diagnosis of recurrent caries. J Am Dent Assoc. 2005;136(10):1426-33.

23. Leinfelder KF. Ask the expert. J Am Dent Assoc. 2000;131(8):1185-7.

24. Kidd EAM. Caries diagnosis within restored teeth. Adv Dent Res. 1990;4(1):10-3.

13. Cavalcante LM, Peris AR, Amaral CM, Ambrosano GM, Pimenta LA. Influence of polymerization technique on micro- 